\title{
Aspects of pneumococcal infection including bacterial virulence, host response and vaccination
}

\author{
S. H. GILLESPIE \\ London School of Hygiene and Tropical Medicine, Keppel Street, London WC1E 7HT
}

\section{Introduction and epidemiology}

\section{Pneumococcal infection - a continuing problem}

The incidence of serious pneumococcal infection remains high : for pneumonia $68-260 / 100000 /$ year; for meningitis $1 \cdot 2-2 \cdot 8 / 100000 /$ year; and for bacteraemia 7-25/100 000/year (Morbidity and Mortality Weekly Review, 1981). The pneumococcus is the most common aetiological agent of communityacquired pneumonia, e.g., $76 \%$ of cases in a recent study from the United Kingdom (MacFarlane $e t$ al., 1982). If only those cases serious enough for admission to an intensive therapy unit are considered, Streptococcus pneumoniae is still the most frequent pathogen and has a mortality rate of $75 \%$ (Woodhead et al., 1985). Of 57000 children under the age of 5 years admitted to hospital in 1983 with acute respiratory infection, some 700 died accounting for $10 \%$ of all deaths in this age group (Lancet, 1985). Fifteen million children died in underdeveloped countries before the age of five, and about one-third of these deaths resulted from acute lower respiratory-tract infections in which S. pneumoniae was probably the principal pathogen. (Lancet, 1985).

Although antibiotics to which this organism is exquisitely sensitive are readily available, the survival rate of invasive pneumococcal infection has not been improved as one might have expected in the antibiotic era. This was demonstrated in the study by Austrian and Gold (1964), who showed that antimicrobial agents did not alter the outcome for a group of patients who had passed a physiological "point-of-no-return", and is further illustrated by a review of mortality in patients with pneumococcal bacteraemia over the last 50 years (summarised in table I). Although these studies are not fully comparable because of the different hospital popu-

Received 16 Aug. 1988; accepted 2 Sep. 1988. lations studied, the consistent trend of high mortality, especially in those $>70$ years old, is apparent.

\section{Carriage of S. pneumoniae}

The pneumococcus is carried in the upper respiratory tract of many healthy individuals. Colonisation begins shortly after birth and by the age of 12 weeks has increased to rates similar to those found in mothers (Riley and Douglas, 1981). Duration of carriage varies slightly; in one study mean duration for serotype 3 was 8.2 weeks whereas that for serotype 19 was 6.0 weeks. Rates of carriage are highest in preschool children and decrease with increasing age. Among adults, the likelihood of pneumococcal carriage depends on the frequency of contact with children. Colonisation increases in frequency during the autumn in temperate countries (Hendley et al., 1975). The carriage of one serotype does not necessarily confer resistance to reacquisition of another strain of the same serotype. In general, $<50 \%$ of carriage results in resistance to re-challenge, e.g., $42 \%$ for serotype 3 and $32 \%$ for serotype 19. The proportion of subjects resistant to colonisation with any one serotype increases with age because of previous colonisation episodes (Dowling et al., 1971).

The spread of pneumococci is proportional to the frequency and intimacy of contact between people and transmission often occurs in conjunction with respiratory viruses. The organism may, therefore, spread rapidly in closed communities and in cramped accommodation such as military barracks. In the special environment of gold mines in South Africa, the rates of carriage of invasive serotypes among miners are high because the community constantly receives new nonimmune subjects who are at an increased risk of pneumonia for 6 months after their arrival in a compound; thereafter, the risk falls dramatically. 
Table I. Changes in mortality from pneumococcal bacteraemia by age and with time

\begin{tabular}{|c|c|c|c|c|c|c|}
\hline \multirow[b]{2}{*}{ Place and time } & \multirow{2}{*}{$\begin{array}{c}\text { Number of } \\
\text { patients }\end{array}$} & \multicolumn{5}{|c|}{ Mortality $(\%)$ in age group } \\
\hline & & $12-29$ & $30-49$ & $50-69$ & $\geqslant 70$ & All \\
\hline Boston, MA, USA 1929-35* & 582 & 48 & 71 & 89 & 100 & 77 \\
\hline Brooklyn, NY, USA 1952-62† & 529 & 8 & 12 & 24 & 54 & 25 \\
\hline Chicago, IL, USA $1967-70 \ddagger$ & 325 & 6 & 19 & 41 & 61 & 28 \\
\hline London, UK $1970-84 \S$ & 325 & 29 & 23 & 28 & 40 & 29 \\
\hline
\end{tabular}

Data taken from studies of *Tilgham and Finland (1937), †Austrian and Gold (1964), Mufson et al. (1974) and §Gransden et al. (1985).

\section{Predisposition to serious pneumococcal infection}

Several host factors are consistently associated with an increased risk of invasive disease: the extremes of age; immunological deficiency, both inherited and acquired; metabolic abnormality; and chronic respiratory disease. Young children have poor responses to carbohydrate antigens and a peak of incidence is found in this age group. The incidence remains low in adult life increasing again among the elderly. Although isolated defects in the chemotactic responses of polymorphonuclear leucocytes (PMNLs) and monocytes, and immunoglobulin or complement deficiencies have been associated with an increased susceptibility to infection, the most significant compromise of immunological function numerically is splenectomy (Wara, 1981). This problem is compounded by a defect in the alternative complement pathway in patients with sickle-cell anaemia. As a result, pneumococcal bacteraemia is a serious threat for children with sickle-cell disease. Alcoholic cirrhosis and diabetes mellitus are the most significant metabolic abnormalities associated with bacteraemia and, in adults, chronic obstructive-airways disease is the most common predisposing respiratory disease. The results of three surveys detailing susceptibility to pneumococcal bacteraemia are summarised in table II (Gruer et al., 1984; Burman et al., 1985; Gransden et al., 1985).

The early use of bactericidal antibiotics by primary health-care physicians has decreased the mortality of pneumococcal infections but has not altered the attack rate. The introduction of an effective vaccine has proved a major advance in the prevention of pneumococcal disease in some patients. However, in many instances the patients most at risk of serious disease respond poorly to the vaccine. Over the last few years there has been a resurgence of interest in the antigenic structure and immunology of the pneumococcus. This review will focus on these studies and the way in which this knowledge might be applied to improve the efficacy of vaccination.

\section{Bacterial virulence determinants}

\section{Capsular polysaccharide (CPS)}

Capsular polysaccharide is an essential virulence determinant of the pneumococcus in the absence of which the lethal inoculum in experimental infection is increased by a factor of $10^{6}$ (Avery and Dubos, 1931). Pneumococcal capsular polysaccharide was the first non-protein antigen shown to be antigenic in man (Dochez and Avery, 1917). The capsule is produced in excess by bacteria in the logarithmic phase of growth and capsular antigens may be detected in the serum and urine of patients with invasive infections. The 83 different polysaccharides described have been classified in two systems; the American System numbers serotypes in the order of first isolation whereas the Danish system groups serotypes which are structurally and immunologically closely related, e.g., serotypes $6 \mathrm{~A}$ and

Table II. Predisposing factors among patients with pneumococcal bacteraemia

\begin{tabular}{lccc}
\hline & \multicolumn{3}{c}{$\begin{array}{c}\text { Number of patients with stated } \\
\text { predisposition among total } \\
\text { number (n) in group studied }\end{array}$} \\
\cline { 2 - 4 } & $\mathrm{A}$ & $\mathrm{B}$ & $\mathrm{C}$ \\
Predisposing factor & $\mathrm{n}=103$ & $\mathrm{n}=411$ & $\mathrm{n}=325$ \\
\hline Chronic chest disorder & 26 & 157 & 63 \\
Alcohol abuse, cirrhosis & 3 & 133 & 72 \\
Haematological malignancy & 9 & 39 & 28 \\
Steroid therapy & 0 & 0 & 28 \\
Diabetes mellitus & 2 & 22 & 11 \\
Splenectomy or sickle cell dis- & 6 & 4 & 19 \\
\multicolumn{1}{c|}{ ease } & & & \\
\hline
\end{tabular}

Data taken from the studies of: A, Gruer et al. (1984); B, Burman et al. (1985); C, Gransden et al. (1985). 
$6 \mathrm{~B}$ differ only in the rhamnosyl-ribitol bond in their linkage (1-3 in 6A and 1-4 in 6B). These structural similarities cause difficulty in the production of monospecific antiserum for accurate serotyping, but work to the advantage of vaccine design in reducing the number of individual serotypes which must be included (Robbins et al., 1983). The Danish system will be used throughout this review.

The capsular polysaccharides may be classified in two main structural groups: (1) linear heteropolymers composed of $\geqslant 2$ monosaccharides as found in types 3 or $19 \mathrm{~F}$; (ii) multichained polysaccharides composed of 2-5 monosaccharides with additional residues. Invasiveness varies among strains and depends on the composition and quantity of capsule produced. Strains of both serotypes 3 and 37 produce large quantities of capsule and have a mucoid appearance on blood agar, but they differ in their ability to cause disease. The former, with a capsule composed of glucose and glucuronic acid, is among the most invasive types and is associated with a poor prognosis, whereas the latter, with a homopolymeric capsule of glucose, is rarely associated with infection. In experimental models with capsular mutant strains of the same serotype but with different amounts of capsule, virulence is found to be proportional to the quantity of capsule produced (Robbins et al., 1983).

Cross-reactions occur with taxonomically unrelated organisms including Escherichia coli, Pseudomonas aeruginosa and $S$. agalactiae (Heidelberger $e t$ al., 1985, 1986). All serotypes are antigenic and most are immunogenic, an important exception being serotype 6 in children. Generation of typespecific antibody heralds recovery from invasive infection (White, 1938). Although the capsule is a principal virulence determinant, the mechanism of its activity is less clear. CPS itself is not toxic to man or animals and its principal action is probably inhibition of phagocytosis. The presence of capsule presents a mechanical barrier preventing complement, deposited on the cell wall, from being opsonically active. In addition, CPS antigen has been shown to inhibit phagocytosis of opsonised bacteria by PMNLs as well as abolishing intracellular killing (Dhingra et al., 1977; Schweinle, 1986).

\section{C-polysaccharide (PnC)}

C-polysaccharide is the major cell-wall component of the pneumococcus. Native C-polysaccharide is a ribitol teichoic acid containing phosphorylcholine and galactosamine; its detailed structure has been elucidated by Jennings et al. (1980). This antigen is covalently bound to the peptidoglycan probably via the muramic acid residue.

Phosphorylcholine is the immunologically dominant epitope, an antigen not usually present among bacteria. Cross-reactions have been found with only a few strains of $S$. mitior, $S$. salivarius and $E$. coli (Mold et al., 1982a, b). However, it is widely distributed among eukaryotic parasitic species including Fasciola, Ascaris, Toxocara (Sugane and Oshima, 1983) and Leishmania (Pritchard et al., 1985), as well as some fungi (Pepys and Longbottom, 1971). C-polysaccharide is also important because it can activate the alternate complement pathway (see Host defences).

Phosphorylcholine is an essential growth factor for pneumococci and, although bacteria continue to grow when choline is substituted by another amino-alcohol, physiological defects soon appear: inability to undergo genetic transformation; resistance to phages; and, most significantly, the inability to divide so that long chains are formed (Briles and Tomasz, 1973). This latter change arises from the resistance of the ethanolamine-containing teichoic acid to pneumococcal N-acetylmuramic acid-Lalanine amidase (autolysin). Interaction with choline residues is essential for the enzymatic hydrolysis of the amide bond between $\mathrm{N}$-acetyl muramic acid and L-alanine (Holtje and Tomasz, 1975).

\section{$F$ antigen}

Phosphorycholine is also incorporated into the $F$ antigen, so called because it is a Forssman antigen capable of evoking sheep red-cell haemolysins when injected into rabbits. Forssman antigens are widely distributed in nature being found in the tissues of mammals, fish and birds and in bacteria. $\mathrm{F}$ antigen is an amphipathic molecule structurally similar to C-polysaccharide, with additional covalently attached lipid material which is a mixture of eight fatty acids one of which may be a hydroxyacid. Lipid makes up 5.7\% of the mol. wt of the antigen and $15 \%$ of choline incorporated into the organism may be found in the F antigen (Briles and Tomasz, 1973).

This pneumococcal antigen is located in the small-vesicle fraction of the plasma membrane (Horne and Tomasz, 1985) as are lipoteichoic acids (LTAs) of other organisms. It has been suggested, therefore, that the $F$ antigen is the functional equivalent of the more conventional membrane LTAs which contain a polyglycerophosphate backbone (Knox and Wicken, 1973). F antigen is a powerful inhibitor of pneumococcal autolysin. Regulation of murein hydrolase activity is a 
function confirmed in other membrane teichoic acids with a polyglycerophosphate backbone. $\mathrm{F}$ antigen produced in cells grown in a medium in which choline has been replaced by ethanolamine is a significantly poorer inhibitor of autolysin. All pneumococci are prone to lysis during the stationary phase of growth, a state that is preceded by release of $\mathrm{F}$ antigen. It is thought that the loss of this powerful regulatory antigen results in the unrestrained activity of the $\mathrm{N}$-acetylmuramic acid-Lalanine amidase (Horne and Tomasz, 1985).

\section{Purpura-producing principle}

Purpura-producing principle was first described by Julianelle and Reiman in 1926 as a component derived from pneumococcal cell walls. This material, which was capable of producing purpura in mice, rabbits and guinea pigs, has a mol. wt of $2.6 \times 10^{7}$, is a complex of peptidoglycan and teichoic acid, and has been shown to be produced by the action of autolysin on the bacterial cell wall (Chetty and Kreger, 1985). Treatment with lysozyme results in inactivation implying that the $\beta$-1, 4-glycosidic linkage is required. It is not known whether the teichoic-acid (PnC) component is needed for biological activity.

\section{Protein antigens and toxins}

Pneumolysin. This sulphydryl-activated toxin has strong sequence homology with the streptolysin-O toxin of $S$. pyogenes and with tetanolysin of Clostridium tetani. It is of $53-56 \mathrm{Kda}$, has a pI of $5 \cdot 2$, and has been found in the cytoplasm of almost all clinical isolates tested (Walker et al., 1987). It has haemolytic activity, which may be inhibited by cholesterol and antibody raised to streptolysin-O, and may have an important role in the pathogenicity of pneumococcal infection. Thus, purified toxin has been shown to inhibit the respiratory burst of PMNLs and monocytes, and the activation of the alternate complement pathway (Nandoskar et al., 1986). Injection of toxoided pneumolysin into mice significantly increased their survival time on lethal challenge with virulent organisms (Paton and Ferrente, 1983; Paton et al., 1983, 1984; Ferrente et al., 1984).

Pneumococcal surface protein $A$. This protein has been found on the surface of many clinical and laboratory strains of pneumococcus. Experiments with monoclocal antibodies directed against this protein have shown that passive immunisation may be protective. No function has been attributed to this antigen, although its loss is associated with loss of virulence (McDaniel et al., 1987).
Neuraminidase. This virulence factor, possessed by many pathogens, has the capacity to damage the host by cleaving terminal sialic-acid residues in glycoproteins, glycolipids and oligosaccharides expressed on host-cell membranes and in body fluids. The concentration of $\mathrm{N}$-acetylneuraminic acid in cerebrospinal fluid can be correlated with coma and adverse outcome in pneumococcal meningitis. Purified pneumococcal neuraminidase is a protein of $107 \mathrm{Kda}$ that is predominantly cell-wall associated. Although it was previously thought that there were several isoenzymes, recent work demonstrated that it is highly susceptible to proteolytic cleavage during purification, resulting in apparent mol. wt heterogeneity (Lock et al., 1988). The pathogenic significance of this enzyme in pneumococcal infection has not been established.

Neutrophil elastase inhibitor. Despite the massive influx of PMNLs during pneumococcal infection and the release of toxic products, there is rarely any derangement of alveolar architecture after recovery. This may be associated with neutrophil elastase inhibitors, two of which are known to be produced by $S$. pneumoniae. One is a negatively charged substance of low mol. wt that depends on an ionic interaction with the cationic elastase. It is substantially inhibited by $\mathrm{NaCl}$ in physiological concentrations and unlikely, therefore, to be important in vivo. A second inhibitor, located on the outside of the bacterial cell membrane has a mol. wt of 140000 . It inhibits elastase non-competitively and is not inhibited by $\mathrm{NaCl}$. Its action is specific; it does not inhibit other elastases or other neutrophil enzymes (Vered et al., 1984). It is sensitive to trypsin and the cleavage products are also biologically active, protecting mice from alveolar damage by neutrophil-granule extracts (Vered et al., 1985). Interaction with elastase is by non-covalent bonds.

\section{Host defences}

\section{Early events}

The integrity of the respiratory epithelium is an important defence against invasion. Mice infected with influenza virus and subsequently challenged with aerosolised virulent pneumococci are resistant to infection until the influenza infection has progressed sufficiently to produce histological damage to the epithelium. $S$. pneumoniae does not adhere to ciliated epithelial cells, but 4-6 days after influenza virus infection the ciliated cells have desquamated. The bacteria then attach readily to the basal cells (Plotkowski et al., 1986).

In the alveolar space, macrophages provide 
defence against inhaled particulate matter. However, they are not able to phagocytose capsulate pneumococci efficiently even when the organisms have been opsonised with $80 \%$ non-immune serum (Jonsson et al., 1985). Once infection is established, there is a massive influx of PMNLs, the stimulus for this being the bacterial cell wall. This response is dose dependent and may occur as a result of chemotactic factors generated via the interaction of C-polysaccharide with the alternate complement pathway (Vial et al., 1984).

\section{The role of the spleen}

Patients who have undergone splenectomy are at greatly increased risk of overwhelming bacterial infections and $S$. pneumoniae is responsible for $>50 \%$ of these episodes. The outcome varies according to the underlying medical condition for which splenectomy was performed. The prognosis is best for those patients who have had splenectomy after trauma, with a poorer prognosis for patients with portal hypertension, sickle-cell anaemia, Hodgkin's disease or other diseases of the reticuloendothelial system (Wara, 1981). The spleen contributes to resistance to pneumococcal infections in several ways. First, it provides a large phagocytic mass for the clearance of poorly opsonised particles; this is important in the early stage of infection before the appearance of specific antibodies. When IgM and IgG appear, pneumococci are preferentially cleared by the liver (Schulkind et al., 1967). The spleen also contributes by enhancing the production of serotype-specific antibodies. Splenectomised patients respond less well to vaccination and infection, and antibody levels decline more quickly. In the mouse model, type-specific antibody concentrations reach a peak 5 days after vaccination, and elevated levels are sustained for $>28$ days. In splenectomised mice, the peak is not reached until 14 days. All antibody responses to serotype- 3 organisms are abolished by splenectomy (Cohn and Schiffman, 1987).

\section{Antibody responses to $S$. pneumoniae}

Capsular polysaccharides. Antibody to CPS is considered to be essential for the survival of an animal challenged with virulent pneumococci. It is the centrality of this antibody response which has made these polysaccharide antigens the main target for vaccine development. In natural infection, typespecific antibody is produced by the sixth day of infection and can usually be detected the first day after crisis (White, 1938). In healthy persons, anti-
CPS antibodies vary with age of the person and in concentration and class specificity also. High $\mathrm{IgG}_{2}$ antibody activity can be found in cord blood and in serum from adults. IgG activity is strongest in children and almost absent in adults. The concentration of IgA antibodies increase steadily with age (Rynnel-Dagöö et al., 1986).

Patients with pneumococcal bacteraemia differ markedly in the concentration of antibody found in serum. One study of 50 adults with bacteraemia showed that some had developed invasive disease despite the presence of preformed specific antibody to CPS. In others antibody concentrations usually rose, but occasionally fell or remained unchanged, in the convalescent period. In those patients with low antibody concentrations, free CPS antigen could be detected in serum (Riley and Douglas, 1981).

After vaccination there is a significant rise in total $\mathrm{IgG}$, predominantly of $\mathrm{IgG}_{1}$ and $\mathrm{IgG}_{2}$ subclasses. In one study, after vaccination with type-3 polysaccharide, the geometric mean titre of $\mathrm{IgG}_{2}$ was significantly higher than those of $\operatorname{IgG}_{1}, \mathrm{IgG}_{3}$ or $\mathrm{IgG}_{4}$. Only the $\mathrm{IgG}_{2}$ post-vaccination titre was statistically significantly greater than the prevaccination concentration (Chudwin et al., 1987).

Children differ in their responses to CPS: for example, serotype-6 strains are often carried for prolonged periods because immune response to this polysaccharide is poor; invasive disease with strains of this type is, therefore, common. Conversely, in adults, type 6 is a good immunogen and invasive disease consequently rare (Robbins et al., 1983). The rank order for the most frequently isolated serotypes from blood in adults is as follows: $8,4,3$, $14,7,12,9,1,18,19,6$ and 23 which together account for $79.8 \%$ of isolates. In children, the rank order is: $14,6,23,19,4,9,7,1,3,8$ and 15 , the first four types being responsible for $60 \%$ of all invasive infections (Robbins et al., 1983).

Studies of mice immunised with an optimal dose of type-3 pneumococci show that the number of plaque-forming cells (PFC) per spleen rises rapidly to a maximum after 4 days; the numbers fall quickly thereafter (Baker et al., 1981). The levels of antibody in the serum do not, however, decline as rapidly owing to the development of extra-splenic antibody synthesis. The initial response to CPS is mostly in the IgM fraction and, of the two types found, one fixes complement and the other requires the addition of class-specific facilitating antiserum. The proportions of $\operatorname{IgG}_{1}, \mathrm{IgG}_{2}$ and $\mathrm{IgA}$ vary depending on the strain of mouse studied (Baker and Stashak, 1969; Barthold et al., 1974; Pasanen et al., 1979). 
CPS is a $T$ cell-independent antigen but treatment of mice with antilymphocyte serum (ALS) results in a delay in the splenic PFC followed by a later enhancement. This is reflected in higher totalantibody concentration after treatment with ALS, an effect eliminated when ALS was absorbed with thymocytes. Since the overall effect cannot be demonstrated in athymic nude mice, it is suggested that $T$ cells are important in the enhancement of antibody responses, although not required for its initiation. It has been proposed that antibody responses to type-3 pneumococci are regulated by two types of $T$ cell, suppressor $\left(T_{S}\right)$ and contrasuppressor cells $\left(\mathrm{T}_{\mathrm{CS}}\right)$ (Baker et al., 1981; BraleyMullen $1986 a$ ). The $T_{C S}$ belong to a unique $T$ cell subset; they are Igh restricted, have antigenbinding receptors and carry the phenotype Lyt1 ${ }^{+}$ $2^{-} \mathrm{L} \mathrm{T} 4^{-} \mathrm{I}^{-} \mathrm{J}^{+} \mathrm{I}-\mathrm{A}^{+}$. Contrasuppressors, which must be compatible with both $T_{S}$ and $B$ cells, have no activity in the absence of $\mathrm{T}$ suppressor cells (Braley-Mullen, 1986a, b).

After vaccination of man, anti-CPS antibodysecreting cells can be detected only when peripheral blood-derived mononuclear-cell (PBMC) cultures are depleted of T cells. In EBV-stimulated cultures depleted of $\mathrm{T}$ cells, anti-CPS antibody-secreting cells can be detected in small numbers in PBMC taken before vaccination. The numbers increase significantly after vaccination, in contrast with the situation occurring when $\mathrm{T}$ cells are not removed, when there is a decrease in the number of secreting cells (Heilmann, 1987).

C-polysaccharide. Antibodies to $\mathrm{PnC}$ have the advantage of being common to all 83 serotypes. Naturally occurring and monoclonal antibodies and myeloma proteins with antiphosphorylcholine (PC) specificity have all been shown to protect mice challenged with virulent pneumococci. Significant levels of antibody to $\mathrm{PnC}$ are uncommon in the first 5 months of life (Briles et al., 1987), but increase steadily thereafter so that nearly all children develop some antibody (IgM) by the age of 4 years (Gray $e t$ $a l ., 1983)$. Antibody levels increase with age and develop in response to carriage and infection (Gray et al., 1983). Of the 83 types of pneumococcus, 56 were shown to produce a measurable change in the anti-PnC antibody level in response to carriage. Stimulation of these antibodies need not necessarily be by pneumococci because similar epitopes are found on other bacteria, fungi and parasites (Pepys and Longbottom, 1971).

Children less than 2 years old respond briskly to $\mathrm{PnC}$, in contrast to their poor antibody response to CPS. A study of 124 patients hospitalised with pneumonia showed that three of six who had $S$. pneumoniae bacteraemia had a significant rise in anti-PnC antibody concentration. Of 44 patients in whom a positive culture was also obtained, $17 \mathrm{had}$ a significant rise in $\mathrm{PnC}$ antibody levels, in comparison to only one of 35 patients whose pneumonia was thought to be caused by another organism (Holmberg et al., 1985).

In mice, as in man, the response to $\mathrm{PnC}$ is dominated by the phosphorylcholine (PC) portion of the molecule. Antibodies are restricted to one of three major idiotype families, T15, M603 and M511 (named by the corresponding prototypic idiotype bearing mouse-myeloma protein). All of the antibodies have a similar $V_{H}$ region (T15), and each of the three families of antibodies has a distinct $V$ region in its light chain. All of the $V_{H}$ regions expressed in mice are derived from the germ-line sequence. Those variants which do occur have arisen by somatic mutation, and this occurs only in IgA and IgG. IgM molecules express the germline T15 V exclusively (Crews et al., 1981). It is not known if human responses are clonally restricted in the same way.

Immunisation of rabbits with non-capsulate pneumococci conferred some degree of active and passive immunity (Tillet, 1928) to different capsulate types in mice. Rabbit polyclonal and mouse monocloncal anti-PC antibodies have been shown to protect mice from fatal challenge (Yother et al., 1982). Amongst the different idiotypes, T15 antibodies are much more protective than the other families, and, of these, IgG antibodies are superior to IgM (Briles et al., 1984). The mechanism of this protection was thought to involve enhancement of opsonisation (McDaniel et al., 1984). Similar protection against challenge with capsulate organisms of different serotypes has also been shown for C-reactive protein (CRP) (Yother et al., 1982).

Antibodies to C-polysaccharide are almost universal in man and, therefore, are not protective in the same way as anti-CPS. PnC is situated deep to the capsule and is not available for opsonisation. Anti-PnC antibody from vaccinated subjects fails to opsonise capsulate strains (Musher et al., 1986) and CRP is not able to enhance opsonisation of capsulate strains above normal serum (Chudwin et al., 1985), but can do so for serotype 27 , which is unique in having a PnC-like epitope in its capsule. The ability of any one serum to opsonise cannot be correlated to CRP or anti-PnC antibody concentrations present (Chudwin et al., 1985).

These contradictory results may have arisen from problems with handling capsulate organisms, exposing cell-wall antigen to opsonisation with CRP or anti-PnC antibody. However, increased survival 
in mice protected with proteins with anti-PC activity has been reproduced on many occasions. It may be that there is a fundamental difference in the immune response between man and mouse. The human response to $\mathrm{PC}$-containing pathogens may be with idiotypes which are not protective, as in the case of the mouse idiotype families M603 and M511. There has been insufficient study of human anti-PC responses to answer this question. Finally, the role of CRP and anti-PC antibodies may not be via complement-dependent opsonisation, but rather by limiting host damage caused by $\mathrm{PnC}$ released from infecting organisms.

\section{Complement}

The role of complement in host resistance to pneumococcal infection is critical. During the course of acute infection patients with severe disease have decreased levels of circulating $\mathrm{C} 3$ and factor $\mathrm{B}$, indicating the consumption of complement together with alternate complement-pathway activation or rapid turnover of factor B (Reed $e t$ al., 1976). Kindreds with inherited deficiencies of C3 are, with one exception, at an increased risk of pneumococcal bacteraemia and septicaemia (Alper et al., 1970). In the same way, increased susceptibility is found in patients with $\mathrm{C} 3 \mathrm{~b}$ inactivator deficiency and combined C2-factor B deficiency (Alper et al., 1970; Abramson et al., 1971; Newman et al., 1978). For mice treated with cobra (Naja naja) venom factor, the lethal dose of $S$. pneumoniae by intraperitoneal injection is reduced by up to 50 times (Winkelstein et al., 1975; Winkelstein, 1981). As in infection with other gram-positive bacteria, opsonisation by the deposition of $\mathrm{C} 3 \mathrm{~b}$ on the bacterial surface is the main way in which complement proteins act; complement is unable to produce bacterial lysis in pneumococci. Although the membrane attack-complex forms normally, it is inserted $10-15 \mathrm{~nm}$ into the peptidoglycan, well short of the 100-nm murein layer of pneumococci (Joiner et al., 1983).

The alternate pathway. Pneumococci are potent activators of the alternate pathway. $\mathrm{PnC}$ is the active cell-wall component because removal of teichoic acid from peptidoglycan diminished complement activation (Winkelstein and Tomasz, 1978). The plasma membrane is also a weak activator of the alternate pathway, an activity residing in the $F$ antigen (Hummell et al., 1985). Pneumococcal capsule can also activate the alternate complement pathway. Serotypes 7, 12, 14 and 25 do so readily but not type 1 . Serotypes 3,4 and 8 also activate this pathway but lose the capacity when cross-reacting antibody is removed. Comple- ment activation by the capsule is $50-100$ times less efficient than with PnC (Fine, 1975).

Studies of the proteolytic degradation of $\mathrm{C} 3 \mathrm{~b}$ covalently bound by pneumococcal capsule indicate variation among serotypes. Serotypes 3 and 4 were shown to have $\mathrm{C} 3 \mathrm{~b}$, iC $3 \mathrm{~b}$ and $\mathrm{C} 3 \mathrm{~d}$ whereas serotypes $6 \mathrm{~A}$ and 14 have only iC $3 \mathrm{~b}$ (Hostetter, 1986). Many studies have sought, therefore, to explain the differences in virulence among serotypes by the ability to fix complement by the alternate pathway. Although such differences are readily demonstrated they do not form a consistent pattern.

Alternate-pathway activation will take place in the absence of specific antibody but the process is enhanced when bacteria are incubated with immunoglobulin isolated from non-immune serum. The specificity of this antibody is not known, but the effect can be removed if serum is absorbed with $E$. coli indicating that the phenomenon may arise from cross-reacting antibodies. (Bjornson et al., $1985)$. This activity is related to the $F\left(a b^{\prime}\right)$ portion of the molecule as the enhancement still occurs when the Fc fragment is removed (Bjornson and Lobel, 1986). It is the absence of this cross-reacting antibody which is responsible for the defect in the alternate pathway found in patients with sickle-cell disease. Complement activation by cell-wall teichoic acid and $\mathrm{F}$ antigen results in the deposition of C3b on the cell wall. However, at this site it is not available to the phagocyte receptors, so limiting its effectiveness in the phagocytic process (Brown et al., 1983).

The classical pathway. Antibodies to CPS of the correct subclass fix complement via the classical pathway. In-vitro experiments with rabbit antibodies against the capsular polysaccharide have been shown to activate $\mathrm{C} 1, \mathrm{C} 4, \mathrm{C} 2$ and $\mathrm{C} 3$ sequentially, depositing $\mathrm{C} 3 \mathrm{~b}$ opsonically on the surface of the organism (Paramen et al., 1979). Paradoxically, experiments with convalescent human serum have failed to show significant activation of the classical pathway, due in part to the class-specific responses to infection. The ability to opsonise can be correlated with total anti-pneumococcal $\operatorname{IgG}_{1}$ and $\mathrm{IgG}_{2}$ (Chudwin et al., 1987). The classical pathway may also be activated by antibodies to other pneumococcal components such as PnC. Interaction of PnC with anti-PnC antibodies or CRP and complement results in activation of the classical pathway, a mechanism possibly important in the early stage of infection when CRP levels are high.

\section{Vaccination}

The first attempt to produce a vaccine against $S$. pneumoniae was made in 1911 by Almroth Wright 
who had previously developed a successful vaccine against typhoid. He initiated six mass-inoculation experiments involving more than 50000 subjects in the South African mines. The vaccine itself was made without regard to serotype and too few organisms were used in its formulation, thus explaining its failure. His work was carried on by Spencer Lister who showed that recovery from pneumococcal infection was accompanied by the development of antibodies to the infecting organism; he concluded that pneumococci existed as a number of serotypes and showed that a minimum of $10^{12}$ organisms was required to stimulate an optimum antibody level. Lister attempted vaccination trials among South African miners, and although he showed a reduction in the attack rate in vaccinated persons from one compound in comparison to unvaccinated ones in another, criticism of the study design left the issue of efficacy a subject of debate (reviewed by Austrian, 1981a, b). In 1945, MacLeod showed that a vaccine containing CPS from strains of serotypes 1, 2, 5 and 7 was highly effective in preventing illness caused by these serotypes among military recruits. This promising development was followed by the production of a hexavalent vaccine, but interest in a pneumococcal vaccine waned after the introduction of penicillin.

The current vaccine is composed of 23 serotypespecific capsular polysaccharides $(50 \mu \mathrm{g}$ each of types $1,2,3,4,5,6 \mathrm{~A}, 6 \mathrm{~B}, 7 \mathrm{~F}, 8,9 \mathrm{~N}, 9 \mathrm{~V}, 10 \mathrm{~A}, 11 \mathrm{~A}$, $12 \mathrm{~F}, 14,15 \mathrm{~B}, 17 \mathrm{~F}, 18 \mathrm{C}, 19 \mathrm{~A}, 19 \mathrm{~F}, 20,22 \mathrm{~F}$ and 23F), a dosage based on the work of MacLeod who showed that $30-60 \mu \mathrm{g}$ of types $1,2,5$ and 7 was required to produce type-specific protection in military recruits (MacLeod et al., 1945). Most healthy adults show at least a two-fold increase in type-specific antibodies within 3 weeks of vaccination. In 23 normal subjects tested 10 years after vaccintion, antibody responses to serotypes 4 and $7 \mathrm{~F}$ remained elevated; but for $1,3,12 \mathrm{~F}, 14$ and $19 \mathrm{~F}$ serotypes, only eight subjects maintained elevated anti-capsular antibodies (Mufson et al., 1987). There is no clear antibody level which might be described as protective; studies of pre- and postvaccination serum showed that, although there were significant rises in total specific immunoglobulin, concentrations could not be correlated with changes in the opsonic ability of serum (Chudwin et al., 1985).

The choice of serotypes for inclusion in the vaccine has been based on surveys of isolations in Europe and North America, taking into account the cross-reactions noted above. Serotypes representing isolates in Brazil, Senegal and Israel were also included in the evaluation (Robbins et al., 1983). The unavailability of reliable serotype data from Third World countries may mean that the vaccine will be less efficient than predicted, if the distribution of serotypes there differs markedly from those in Europe and North America. There is no doubt that pneumococcal vaccination is highly efficient in a young, immunologically competent population at high risk of pneumococcal disease (Schwartz, 1982). The efficacy is less clear when there is compromise of the immune system.

As has been noted, development of antibody to CPS requires a functional splenic mass and patients with splenectomy respond less well to the vaccine than normal subjects. However, protective levels of antibody can be stimulated in $80 \%$ of patients, but these levels may decline rapidly (Giebink et al., 1984). There is probably little difference in the antibody level developed following vaccination among groups splenectomised for traumatic, haematologic or other immunological indications. Timing of vaccination with respect to splenectomy is probably not critical, but because antibody responses afterwards may be impaired, vaccination before operation is preferred. Revaccination of splenectomised patients may be beneficial, because it has been shown that the percentage of subjects with a protective level of antibody to serotypes $6 \mathrm{~A}$, 14 and 19 can be increased from 74,44 and $79 \%$ to 92,66 and $92 \%$, respectively (Kaplan et al., 1986).

Children less than 2 years old respond poorly to polysaccharide antigens. Serotypes included in the vaccine may be classified as strongly immunogenic in children of all ages, as age-dependent immunogens (19F and $18 \mathrm{C}$ ), or as uniformly poor immunogens (6A and 23F) (Leinonen et al., 1986). In a large study of children less than 5 years old in Papua New Guinea, where acute respiratory infection is the commonest cause of death, children were vaccinated between 6 months and 5 years of age. The efficiency of vaccination in reducing death from acute lower respiratory tract infections was estimated at 59\% and 50\% in children less than 5 and 2 years, respectively. There was a significant difference in the mortality in the vaccinated group compared with that in a placebo-control group (Riley et al., 1986).

Other trials of vaccine efficiency in high-risk groups (such as the elderly) have often been disappointing. In one study of 89 patients, there was no difference in bacteraemic rates in vaccinated subjects compared with control subjects (Forrester et al., 1987). Moreover, $65 \%$ of blood-isolate types from non-vaccinated patients were included in the vaccine compared with $69 \%$ of those in the 
vaccinated group. A randomised double-blind placebo-controlled trial in 2295 high-risk patients ( $>55$ years old and with chronic cardiac, pulmonary, hepatic or renal disease, alcoholsism or diabetes mellitus) has been performed. Of 63 proven or probable invasive infections, 27 were placebo and 36 vaccine recipients. In the vaccine group 14 infections were caused by serotypes contained in the vaccine. Vaccine failure probably occurred because subjects did not make, or sustain, serum antibodies to their infecting organism (Simberkoff et al., 1986). A recent study of elderly subjects without immune compromise showed a $70 \%$ vaccine efficiency. It is clear, therefore, that vaccination provides useful protection to those patients immunologically competent to respond, but for patients at highest risk alternative vaccine strategies must be found (Sims et al., 1988).

\section{New developments}

Alternative vaccine strategies may be considered in three main areas: development of pneumococcal protein vaccine candidates; enhancement of responses to CPS vaccine by cojugation with protein antigens: and enhancement of $\mathrm{PnC}$-antibody responses. These approaches are not necessarily mutually exclusive and the provision of an improved vaccine might involve several of these stategies.

Several groups are investigating protein antigens including pneumococcal surface-protein $\mathrm{A}$, the loss of which results in a loss of virulence. Mice may be partially protected by immunisation with this antigen and passive immunity with monoclonal

\section{REFERENCES}

Abramson N, Alper C A, Lachmann P J, Rosen F S, Jandl J H 1971 Deficiency of C3 inactivator in man. Journal of Immunology 107: 19-27.

Alper C A, Abramson N, Johnston R B, Jandl J H, Rosen F S 1970 Studies in vitro and in vivo on an abnormality in the metabolism of $\mathrm{C} 3$ in a patient with an increased susceptibility to infection. Journal of Clinical Investigation 49 : 19751985.

Austrian R, Gold J 1964 Pneumococcal bacteremia with especial reference to bacteremic pneumococcal pneumonia. Annals of Internal Medicine 60: 759-776.

Austrian R 1981a Pneumococcus: The first hundred years. Reviews of Infectious Diseases 3: 183-189.

Austrian R $1981 b$ Some observation on the pneumococcus and on the current status of pneumococcal disease and its prevention. Reviews of Infectious Diseases 3 Suppl. : S1-S17.

Avery O T, Dubos R 1931 The protective action of a specific enzyme against type-III pneumococcus infection in mice. Journal of Experimental Medicine 54: 73-89.

Baker P J, Stashak P W 1969 Quantitative and qualitative studies on the primary antibody response to pneumococcal antibody against surface protein is also partially protective (McDaniel et al., 1987). Pneumolysin, which has been cloned and sequenced, is a protein antigen known to protect mice.

Linking an oligosaccharide from serotype-6 material to the non-toxic diphtheria protein from mutant strain CRM197 rendered it highly immunogenic (Porro et al., 1985). This method might be used to improve the antibody responses to other poorly immunogenic types.

Antibodies to PC have been shown to be protective in mouse models. Attempts to enhance immunity have been made with purified $\mathrm{PnC}$, ovalbumin-PC, and KLH-PC. An idiotype vaccine has been developed to the PC epitope (Wallick et al., 1983; Ward et al., 1987). All of these strategies have enhanced mouse resistance to infection but, as has been noted, their applicability to man is still controversial.

\section{Concluding remarks}

$S$. pneumoniae is still one of the most important organisms infecting man. Much has been learnt about the organism and human immune responses to it in the last 100 years. However, our understanding of some aspects of pathogenesis, notably events occurring early in the course of infection, is poor. Growth areas in research are likely to include: factors transforming carriage into invasive infection; the role of alveolar macrophages and PMNL in the lung; the role of preformed anti-PC antibodies, CRP, and antibodies to protein antigens which might enhance species-specific resistance to infection.

polysaccharides at the cellular level. Journal of Immunology 103: 1342-1348.

Baker P J, Amsbaugh D F, Stashak P W, Caldes G, Prescott B 1981 Regulation of the antibody response to the pneumococcal polysaccharide by thymus-derived cells. Reviews of Infectious Diseases 3: 332-341.

Barthold D R, Prescott B, Stashak P W, Amsbaugh D F, Baker P J 1974 Regulation of the response to type-III pneumococcal polysaccharide. III Role of regulatory $T$ cells in development of an $\operatorname{IgG}$ and $\operatorname{IgA}$ response. Journal of Immunology 112: 1042-1050.

Bjornson A B, Lobel J S 1986 Lack of a requirement for the Fc region of the $\mathrm{IgG}$ in restoring pneumococcal opsonization via the alternative complement pathway in sickle cell disease. Journal of Infectious Diseases 154: 760-769.

Bjornson A B, Lobel J S, Harr K S 1985 Relation between serum opsonic activity for Streptococcus pneumoniae and complement function in sickle cell disease. Journal of Infectious Diseases 152: 701-709.

Braley-Mullen H $1986 a$ Requirements for activation of contrasuppressor T cells by type-III pneumococcal polysaccharide. Journal of Immunology 136: 396-401.

Braley-Mullen H $1986 b$ Characterization and activity of contra- 
suppressor $\mathrm{T}$ cells induced by type-III pneumococcal polysaccharide. Journal of Immunology 137: 2761-2767.

Briles E B, Tomasz A 1973 Pneumococcal Forssman antigen. A choline-containing lipoteichoic acid. Journal of Biological Chemistry 248: 6394-6397.

Briles D E, Formann D, Hudak S, Claflin J L 1984 The effects of idiotype on the ability of $\mathrm{IgG}_{1}$ anti-phophorylcholine antibodies to protect mice from fatal infection with Streptococcus pneumoniae. European Journal of Immunology 14: $1027-1030$.

Briles D E et al. 1987 Naturally occuring antibodies to phosphocholine as a potential index of antibody responsiveness to polysaccharides. Journal of Infectious Diseases 155 : 1307-1314.

Brown E J, Joiner K A, Cole R M, Berger M 1983 Localization of complement component 3 on Streptococcus pneumoniae: anti-capsular antibody causes complement deposition on the pneumococcal capsule. Infection and Immunity 39: 403409.

Burman L A, Norrby R, Trollfors B 1985 Invasive pneumococcal infections: incidence, predisposing factors, and prognosis. Reviews of Infectious Diseases 7: 133-142.

Chetty C, Kreger A 1985 Generation of purpura-producing principle from pneumococcal cell walls. Journal of Bacteriology 163 : 389-391.

Chudwin D S, Artrip S G, Korenblit A, Schiffman G, Rao S 1985 Correlation of serum opsonins with in-vitro phagocytosis of Streptococcus pneumoniae. Infection and Immunity 50: 213-217.

Chudwin D S, Artrip S G, Schiffman G 1987 Immunoglobulin $\mathrm{G}$ class and subclass antibodies to pneumococcal capsular polysaccharides. Clinical Immunology and Immunopathology 44: 114-121.

Cohn D A, Schiffman G 1987 Immunoregulatory role of the spleen in the antibody responses to pneumococcal polysaccharide antigens. Infection and Immunity 55: 1375-1380.

Crews S, Griffin J, Huang H, Calame K, Hood L 1981 A single VH gene segment encodes the immune response to phosphocholine: somatic mutation is correlated with the class of the antibody. Cell 25: 59-66.

Dhingra R K, Williams J C, Reed W P 1977 Effect of pneumococcal mucopeptide and capsular polysaccharide on phagocytosis. Infection and Immunity 15: 169-174.

Dochez A R, Avery O T 1917 The elaboration of specific soluble substance by pneumococci during growth. Journal of Experimental Medicine 26: 477-493.

Dowling J N, Sheehe P R, Feldman H A 1971 Pharyngeal pneumococcal acquisitions in "normal" families: a longitudinal study. Journal of Infectious Diseases 124: 9-17.

Ferrante A, Rowan-Kelly B, Paton J C 1984 Inhibition of invitro human response by the pneumococcal toxin pneumolysin. Infection and Immunity 46: 585-589.

Fine D P 1975 Pneumococcal type-associated variability in alternate complement pathway activation. Infection and Immunity 12: 772-778.

Forrester H L, Jahnigen D W, LaForce F M 1987 Inefficacy of pneumococcal vaccine in a high-risk population. American Journal of Medicine 83: 425-430.

Giebink G S, Le C T, Schiffman G 1984 Decline of serum antibody in splenectomized children after vaccination with pneumococcal capsular polysaccharides. Journal of Pediatrics 105 : 576-582.

Gransden W R, Eykyn S J, Phillips I 1985 Pneumococcal bacteraemia: 325 episodes diagnosed at St Thomas's Hospital. British Medical Journal 290 : 505-508.

Gray B M, Dillon H C, Briles D E 1983 Epidemiological studies of Streptococcus pneumoniae in infants: development of antibody to phosphocholine. Journal of Clinical Microbiology 18: 1102-1107.

Gruer L D, McKendrick M W, Geddes A M 1984 Pneumococcal bacteraemia-a continuing challenge. Quarterly Journal of Medicine 53: 259-270.

Heidelberger M, Jann K, Jann B 1985 Crossreactions of Escherichia coli $\mathrm{K}$ and $\mathrm{O}$ polysaccharides in anti-pneumococcal and anti-Salmonella sera. Journal of Experimental Medicine 162: 1350-1358.

Heidelberger M, Horton D, Haskell T H 1986 Cross-reactions of lipopolysaccharides of Pseudomonas aeruginosa in antipneumococcal and other antisera. Infection and Immunity 54 : 928-930.

Heilmann C 1987 Vaccination-induced activation of human blood $\mathrm{T}$ cells supressing pneumococcal polysaccharidespecific B cells. Acta Pathologica Microbiologica et Immunologica Scandinavica (C) 95: 65-69.

Hendley J O, Sande M A, Stewart P M, Gwaltney J M 1975 Spread of Streptococcus pneumoniae in families. I. Carriage rates and distribution of types. Journal of Infectious Diseases 132: $55-61$.

Holmberg H, Krook A, Sjogren A-M 1985 Determination of antibodies to pneumococcal $\mathbf{C}$ polysaccharide in patients with community-acquired pneumonia. Journal of Clinical Microbiology 22: 808-814.

Holtje J-V, Tomasz A 1975 Specific recognition of choline residues in the cell wall teichoic acid by the $\mathrm{N}$-acetylmuramyl-L-alanine amidase of pneumococcus. Journal of Biological Chemistry 250: 6072-6076.

Horne D, Tomasz A 1985 Pneumococcal Forssman antigen: enrichment in mesosomal membranes and specific binding to the autolytic enzyme of Streptococcus pneumoniae. Journal of Bacteriology 161 : 18-24.

Hostetter M K 1986 Serotypic variations among virulent pneumococci in deposition and degradation of covalently bound $\mathrm{C} 3 \mathrm{~b}$ : implications for phagocytosis and antibody production. Journal of Infectious Diseases 153: 682-693.

Hummell D S, Swift A J, Tomasz A, Winkelstein J A 1985 Activation of the alternative complement pathway by pneumococcal lipoteichoic acid. Infection and Immunity 47: 384-387.

Jennings H J, Lugowski C, Young N M 1980 Structure of the complex polysaccharide C-substance from Streptococcus pneumoniae type I. Biochemistry $19: 4712-4719$.

Joiner K, Brown E, Hammer C, Warren K, Frank M 1983 Studies on the mechanism of bacterial resistance to complement-medicated killing III C $5 \mathrm{~b}-9$ deposits stably on rough and type $7 S$. pneumoniae without causing bacterial killing. Journal of Immunology 130; 845-849.

Jonsson S, Musher D M, Chapman A, Goree A, Lawrence E C 1985 Phagocytosis and killing of common bacterial pathogens of the lung by human alveolar macrophages. Journal of Infectious Diseases 152 : 4-13.

Kaplan J, Sarnaik S, Schiffman G 1986 Revaccination with polyvalent pneumococcal vaccine in children with sickle cell anemia. American Journal of Pediatric Hematology and Oncology 8: 80-82.

Knox K W, Wicken A J 1973 Immunological properties of teichoic acids. Bacteriological Reviews 37: 215-257.

Lancet (leading article) 1988 Acute respiratory infections in under-fives: 15 million deaths a year. Lancet 2: 699-701.

Leinonen M, Sakkinen A, Kalliokoski R, Luotonen J, Timonen M, Mäkelä P H 1986 Antibody response to 14-valent pneumococcal capsular polysaccharide vaccine in preschool age children. Pediatric Infectious Diseases 5 : 39-44.

Lock R A, Paton J C, Hansman D 1988 Purification and immunological characterization of neuraminidase pro- 
duced by Streptococcus pneumoniae. Microbial Pathogenesis 4: $33-43$.

MacLeod C M, Hodges R G, Heidelberger M, Bernherd W G 1945 Prevention of pneumococcal pneumonia by immunisation with specific capsular polysaccharides. Journal of Experimental Medicine 82: 445-465.

MacFarlane J T, Finch R G, Ward M J, Macrae A D 1982 Hospital study of adult community-acquired pneumonia. Lancet 2: 255-258.

McDaniel L S, Benjamin W H, Forman C, Briles D E 1984 Blood clearance by anti-phosphocholine antibodies as a mechanism of protection in experimental pneumococcal bacteremia. Journal of Immunology 133: 3308-3312.

McDaniel L S, Yother J, Vijayakumar M, McGarry L, Guild W R, Briles D E 1987 Use of insertional inactivation to facilitate studies of biological properties of pneumoncoccal surface protein A (PspA). Journal of Experimental Medicine 165: $381-394$.

Mold C, Edwards K M, Gewurz H. 1982a Effect of C-reactive protein on the complement-mediated stimulation of human neutrophils by Streptococcus pneumoniae serotypes 3 and 6 . Infection and Immunity 37: 987-992.

Mold C, Rodgers C P, Kaplan R L, Gewurz H $1982 b$ Binding of C-reactive protein to bacteria. Infection and Immunity 38 : 392-395.

Morbidity and Mortality Weekly Report 198130 : (33) 410.

Mufson M A, Krausa H E, Schiffman G, Hughey D F 1987 Pneumococcal antibody levels one decade after immunization of healthy adults. American Journal of Medical Science 293: 279-284.

Mufson M A, Kruss D M, Wasil R E, Metzger W I 1974 Capsular types and outcome of bacteremic pneumococcal disease in the antibiotic era. Archives of Internal Medicine 134: 505-509.

Musher D M, Chapman A J, Goree A, Jonsson S, Briles D, Baughn R E 1986 Natural and vaccine-related immunity to Streptococcus pneumoniae. Journal of Infectious Diseases 154 : 245-256.

Nandoskar M, Ferrante A, Bates E J, Hurst N, Paton J C 1986 Inhibition of human monocyte respiratory burst, degranulation, phospholipid methylation and bacteriocidal activity by pneumolysin. Immunology 59: 515-520.

Newman S L, Vogler L B, Feigin R D, Johnston R B 1978 Recurrent septicemia associated with congenital deficiency of $\mathrm{C} 2$ and a partial deficiency of factor $\mathrm{B}$ and the alternative complement pathway. New England Journal of Medicine 299: $290-292$

Pasanen, V. J., Asofsky T, Baker P J 1979 Synthesis of two classes of antibody $\mathrm{I} \gamma \mathrm{M}$ and $\mathrm{I} \gamma \mathrm{G}$ or $\mathrm{I} \gamma \mathrm{M}$ and $\mathrm{I} \gamma \mathrm{A}$ by identical cells: amplification of the antibody response to pneumococcal polysaccharide type III. Journal of Experimental Medicine 149: 1227-1237.

Paton J C, Ferrante A 1983 Inhibition of human polymorphonuclear leukocyte respiratory burst, bacteriocidal activity and migration by pneumolysin. Infection and Immunity 41: $1212-1216$.

Paton J C, Lock R A, Hansman D J 1983 Effect of immunization with pneumolysin of survival time in mice challenged with Streptococcus pneumoniae. Infection and Immunity 40: 548552.

Paton J C, Rowam-Kelly B, Ferrante A 1984 Activation of human complement by the pneumococcal toxin pneumolysin. Infection and Immunity 43: 1085-1087.

Pepys J, Longbottom J L 1971 Antigenic and C-substance activities of related glycopeptides from fungal, parasitic and vegetable sources. International Archives of Allergy and Applied Immunology 41 : 219-221.
Plotkowski M-C, Puchelle E, Beck G, Jacquot J, Hannoun C 1986 Adherence of type I Streptococcus pneumoniae to tracheal epithelium of mice infected with influenza A/PR8 virus. American Review of Respiratory Diseases 134: 1040 1044.

Porro M, Costantino P, Viti S, Vannozzi F, Naggi A, Torri G 1985 Specific antibodies to diphtheria toxin and type $6 \mathrm{~A}$ pneumococcal capsular polysaccharide induced by a model of semi-synthetic glyconconjugate antigen. Molecular Immunology 22: 907-919.

Pritchard D G, Volanakis J E, Slutsky G M, Greenblatt C L 1985 C-Reactive protein binds leishmanial excreted factors. Proceedings of the Society for Experimental Biology and Medicine 178: 500-503.

Reed W P, Davidson M S, Williams R C 1976 Complement system in pneumococcal infections. Infection and Immunity 13: $1120-1125$.

Riley I D, Douglas R M 1981 An epidemiologic approach to pneumococcal disease. Reviews of Infectious Diseases 3: 233-245.

Riley I D, Lehmann D, Alpers M P, Marshall T F de C, Gratten H, Smith D 1986 pneumococcal vaccine prevents death from acute lower-respiratory-tract infections in Papua New Guinean Children. Lancet 2: 877-881

Robbins J B et al. 1983 Consideration for formulating the second-generation pneumococcal capsular polysaccharide vaccine with emphasis on the cross-reactive types within groups. Journal of Infectious Diseases 148: 1136-1159.

Rynnel-Dagöö B, Freijd A, Hammarström L, Oxelius V, Persson M A, Smith C I 1986 Pneumococcal antibodies of different immunoglobulin subclasses in normal and IgG subclass deficient individuals of various ages. Acta Otolaryngologica 101 : 146-151.

Schwartz J S 1982 Pneumococcal vaccine: clinical efficacy and effectiveness. Annals of Internal Medicine 96 : 208-220.

Schulkind M L, Ellis E F, Smith R T 1967 Effect of antibody on the clearance of ${ }^{125} T$ labelled pneumococci by the spleen and liver. Pediatric Research 1 : 178-184.

Schweinle J E 1986 Pneumococcal intracellular killing is abolished by polysaccharides despite serum complement activity. Infection and Immunity 54: 876-881.

Simberkoff M S et al. 1986 Efficacy of pneumococcal vaccine in high-risk patients. Results of a veterans administration cooperative study. New England Journal of Medicine 315: $1318-1327$

Sims R V, Steinmann W C, McConville J H, King L R, Zwick W C, Schwartz J S 1988 The clinical effectiveness of pneumococcal vaccination in the elderly. Annals of Internal Medicine 108: 653-657.

Sugane K, Oshima T 1983 Activation of complement in Creactive protein positive sera by phosphorylcholine-bearing component isolated from parasite extract. Parasite Immunology 5 : 385-395.

Tilghman R C, Finland M 1937 Clinical significance of bacteremia in pneumococcic pneumonia. Archives of Internal Medicine 59: 602-619.

Tillet W S 1928 Active and passive immunity to pneumococcus infection induced in rabbits by immunization with pneumococci. Journal of Experimental Medicine 48: 791-804.

Vered M, Dearing R, Janoff A 1985 A new elastase inhibitor from Streptococcus pneumoniae protects against acute lung injury induced by neutrophil granules. American Review of Respiratory Disease 131 : 131-133.

Vered M, Schutzbank T, Janoff A 1984 Inhibitors of human neutrophil elastase in extracts of Streptococcus pneumoniae. American Reviews of Respiratory Disease 130: 1118-1124.

Vial W C, Toews G B, Pierce A K 1984 Early pulmonary 
granulocyte recruitment in response to Streptococcus pneumoniae. American Review of Respiratory Disease 129: 87-91.

Walker J A, Allen R L, Falmagne P, Johnson M K, Boulnois G J 1987 Molecular cloning, characterization, and complete nucleotide sequence of the gene for pneumolysin, the sulfhydryl-activated toxin of Streptococcus pneumoniae. Infection and Immunity 55: 1184-1189.

Wallick S, Claflin J L, Briles D E 1983 Resistance to Streptococcus pneumonia is induced by a phosphocholine-protein conjugate. Journal of Immunology 130: 2871-2875.

Wara D W 1981 Host defense against Streptococcus pneumoniae: the role of the spleen. Reviews of Infectious Diseases 3: 299309.

Ward M M, Ward R E, Huang J-H, Kohler H 1987 Idiotype vaccine against Streptococcus pneumoniae. A precursor study. Journal of Immunology 139: 2775-2780.

White B 1938 The biology of the pneumococcus; the bacteriological, biochemical and immunological character and activi- ties of Diplococcus pneumoniae. The Commonwealth Fund. New York.

Winkelstein J A 1981 The role of complement in the host's defense against Streptococcus pneumoniae. Reviews of Infectious Diseases 3: 289-298.

Winkelstein J A, Tomasz A 1978 Activation of the alternative complement pathway by pneumococcal cell wall teichoic acid. Journal of Immunology 120 : 174-178.

Winkelstein J A, Smith M R, Slim H S 1975 The role of C3 as an opsonin the early stages of infection. Proceedings of the Society for Experimental Biology and Medicine 149: 397-401.

Woodhead M A, MacFarlane J T, Rodgers F G, Laverick A, Pilkington R, Macrae A D 1985 Aetiology and outcome of severe community-acquired pneumonia. Journal of Infection 10: 204-210.

Yother J, Volanakis J E, Briles D E 1982 Human C-reactive protein is protective against fatal Streptococcus pneumoniae infection in mice. Journal of Immunology 128: 2374-2376. 